\title{
Factors influencing HIV counselling and testing uptake among corps members in Osun State, Nigeria
}

\author{
*Eyitope O. Amu ${ }^{1}$, Foluke A. Olatona ${ }^{2}$ and Adedeji A. Onayade ${ }^{3}$ \\ ${ }^{I}$ (Department of Community Medicine, Ekiti State University Teaching Hospital, Ado-Ekiti, Nigeria) \\ ${ }^{2}$ (Department of Community Health, Lagos University Teaching Hospital, Lagos, Nigeria) \\ ${ }_{3}^{3}$ (Department of Community Health, Obafemi Awolowo University, Ile-Ife, Nigeria)
}

\begin{abstract}
The prevalence of HIV infection among Nigerian youths has been persistently high and HIV Counselling and Testing (HCT) is a major intervention that can help to reduce the transmission of HIV. This study was carried out to determine the uptake of HCT and identify the factors affecting the uptake among National Youth Service Corps (NYSC) members in Osun State, Nigeria. The study employed a cross-sectional analytical design. A pre-tested, self-administered, semi-structured questionnaire was used to elicit information from 1000 corps members who were recruited by systematic random sampling at the NYSC orientation camp Osun State. Factors affecting HCT uptake were evaluated using binary logistic regression analysis, confidence intervals and odd ratios. The results showed that 59.0\% of the respondents had HCT while $41.0 \%$ had never accessed HCT before. The factors influencing uptake among the respondents were risk perception $(p=0.002)$ and partner's screening status $(p<0.001)$. HCT uptake among the respondents was fair. Personal and partner factors predicted HCT uptake. Health education to make people appreciate their risk of HIV and importance of HCT should be intensified.
\end{abstract}

Keywords: Corps members, HIV, HIV counseling, HIV testing, Osun State

\section{Introduction}

The number of people living with Human Immuno Deficiency Virus is increasing steadily with subSaharan Africa being more severely affected. Worldwide, it is estimated that 38 million people are infected with HIV, with over $90 \%$ in developing countries and $64 \%$ in sub-Saharan Africa alone ${ }^{[1]}$ Youth aged $10-24$ years, which comprise about one-fifth of the world's population are the worst group affected with HIV/AIDs. Young people aged 15 to 24 years account for about $30 \%$ of all people living with HIV/AIDS and a half of all new HIV infections ${ }^{[1]}$

It has caused a lot of devastations to individuals, families, communities and countries ${ }^{[2,3]}$ HIV/AIDS affects the health and wealth of households as well as infected individuals ${ }^{[4]}$ It can lead to decreased participation in formal education of young people, along with depleted family income due to loss of work, and eventually poverty. Poor disease management presents additional vulnerabilities ${ }^{[5]}$

Nigeria is one of the countries most affected. It has over three million infected people and a seroprevalence rate of $4.6 \%{ }^{[6]}$ Over a period of 20 years, more than 60 million people have been infected with HIV and more than half of those newly infected are young people between 15 and 29 years old with the females more affected ${ }^{[7]}$ Since 1995, HIV prevalence rates among the youth in the most-affected states have increased considerably ${ }^{[8]}$ Sero-prevalence survey shows that the prevalence among those aged $20-24$ years is $4.6 \%$ while that of $25-29$ year olds is $5.6 \% .^{[6]}$

Voluntary Counselling and Testing is a major intervention that can help to reduce the transmission of HIV ${ }^{[9]}$ It provides accurate and timely information about HIV/AIDS; identifies those affected by HIV for prompt care and treatment and encourage behavior change among those who are not affected. The number of people accessing the services is however still low. The 2005 National HIV/AIDS and Reproductive Health Survey (NARHS) revealed that only $11 \%$ of females and $12 \%$ of males had ever taken the HIV test. ${ }^{[10]}$

A study conducted among some students of some higher institutions in Osun State showed that only 5\% of them knew their status ${ }^{[11]}$

Studies have shown that risky sexual behaviour that can predispose to HIV is high in Nigerian universities. ${ }^{[12]}$ However, little is known about HCT uptake and associated factors among corps members who have just graduated from these universities. Corps members are new graduates from higher institutions of learning and therefore present a good picture of students in the higher institutions. Moreover, they provide a rich mix of persons since they represent diverse ethnic and cultural backgrounds in Nigeria. This study was therefore conducted to determine the factors associated with acceptance and uptake of HCT among National Youth Corps Service members in Osun state Nigeria. The result will help policy makers to identify factors to be targeted for prevention of HIV AIDS. 


\section{Methods}

The study location was Osun State, in the Southwest of Nigeria. The NYSC Corps members are usually posted to each state yearly. The study employed an analytical cross-sectional design. Assuming a $95 \%$ level of confidence, an estimate of HCT uptake of $17.8 \%$ and a maximum acceptable difference from true proportion of $5 \%$, the formula for estimating single proportions was used to obtain the minimum estimated sample size of 225 . A total of 1000 participants were eventually interviewed.

Respondents were recruited using systematic sampling technique. There were a total of two thousand five hundred corps members, divided into twenty platoons of one hundred and twenty five corps members each, at the orientation camp. The corps members in each platoon were given serial numbers from 1 to 125 . Using simple random sampling method, a number was picked randomly between 1 and 3 . The corps member whose NYSC number corresponded with that serial number was recruited first. Using a sampling interval of three (3), fifty corps members were selected from each platoon.

A pre-tested, semi-structured, self administered questionnaire which elicited information on respondents' socio-demographic characteristics, knowledge of HIV/AIDS, knowledge and attitude to HCT and HCT uptake was used. Ethical approval was obtained from the Ethics and Research Committee of the Obafemi Awolowo University Teaching Hospital, Ile-Ife. Permission to carry out the study was obtained from the State NYSC Director. Written informed consent was obtained from each respondent prior to data collection.

Data were analysed using the Statistical Package for Social Sciences version 15. Continuous data such as age were summarized as means. Discrete data were summarized as proportions and presented as frequency tables. Binary logistic regression was used to demonstrate the association between the independent, intermediate and dependent variables. Odds Ratios and 95\% Confidence Intervals (CI) were generated for the explanatory variables. A p value $<0.05$ was considered statistically significant. The independent variables included in the analysis were religion and ethnicity while the intermediate variables included knowledge of HIV, perception that HCT has advantages/benefits, perception that HCT has disadvantages, risk perception for HIV, prior sexual experience and sexual partner's screening status. The dependent variable, HCT uptake was measured by asking respondents whether they had been tested for HIV before or not.

\section{Results}

A total of 861 out of 1000 questionnaires administered were correctly filled and returned (response rate of $86.1 \%$ ). The respondents were aged between 20-32 years; the mean age (SD) was 25.8 (3.3) years and most of them $(70.4 \%)$ were in the $25-29$ year old age group category. There were slightly more males $(54.7 \%)$ than females (45.3\%); $83 \%$ were Christians, $15 \%$ were Muslims while the rest belonged to other faiths. Most (84\%) were of non Yoruba origin: Igbo 33.7\%, Hausa $8.9 \%$ and other ethnic origins $41.3 \%$. Thirty percent studied Social Sciences; $15.7 \%$ Pure and Applied Sciences and 10\% Engineering. The rest studied other courses.

Table 1 shows respondents' HCT uptake and their reasons for accessing HCT. Five hundred and eight (59.0\%) of the respondents had been tested for HIV while the rest had not. The three most important reasons for having HCT were: in order to know their HIV status (59.8\%), to reduce fear and anxiety (18.7\%) and concern about risk of infection (18.1\%).

Table 2 shows reasons for not accessing HCT among those respondents who had not been tested for HIV. The three most important reasons were: perception that they were not at risk of being infected $(80.5 \%)$, fear of testing positive (19.5\%) and perception of being healthy without a need for HCT (18.7\%).

Table 3 shows the binary logistic regression model assessing the association between selected explanatory variables and $\mathrm{HCT}$ uptake (the dependent variable). Explanatory variables correlating with each other, for example, knowledge of HIV and knowledge of HCT were not entered together to avoid multi colinearity. The significant predictors of HCT uptake were risk perception for HIV and partner's screening status. Compared with respondents who felt they had no risk of HIV, those who perceived they had small risk, those unsure of their risk and those that had moderate risk were more likely to access HCT. However only those of moderate risk was significant $\{\mathrm{OR} 2.47,(95 \% \mathrm{CI}=1.38-4.42)$; $\mathrm{p}=0.002\}$ Those who perceived themselves as being of great risk were actually less likely to have HCT compared with those who felt that had no risk at all. Compared with respondents whose partners had been screened, those who were not sure whether their partners had been screened $\{$ OR 0.25 (95\% CI $=0.17-0.36) ; \mathrm{p}<0.001\}$, those who had no partners $\{\mathrm{OR} 0.21$ (95\% $\mathrm{CI}=0.13-0.35$ ); $\mathrm{p}<0.001\}$ and those whose partners had not been screened $\{\mathrm{OR} 0.22$ (95\%CI $0.14-0.34$ ); $\mathrm{p}<0.001\}$ were all less likely to have HCT. 
Table 1: HCT uptake and reasons for accessing HCT among respondents

\begin{tabular}{lc}
\hline HCT Uptake & $\begin{array}{l}\text { Freq (\%) } \\
\mathbf{n = 8 6 1}\end{array}$ \\
Has been tested for HIV & $508(59.0)$ \\
Has not been tested for HIV & $353(41.0)$ \\
Total & 861 \\
\hline Reasons for accessing HCT by respondents & $\mathbf{n = 5 0 8 *}$ \\
To know HIV status & $304(59.8)$ \\
To reduce fear and anxiety & $95(18.7)$ \\
Concern about risk of infection & $92(18.1)$ \\
Sequel to being sick /frequent illnesses & $63(12.4)$ \\
Prior to blood donation & $60(11.8)$ \\
Marriage purposes & $49(9.6)$ \\
Requirement for admission and employment purposes & $66(13.1)$ \\
Partner died of AIDS & $3(0.6)$ \\
*There were multiple responses &
\end{tabular}

Table 2: Reasons for not accessing HCT among respondents who had not been tested for HIV

\begin{tabular}{ll}
\hline Reasons & $\begin{array}{c}\text { Freq (\%) } \\
\mathbf{n = 3 5 3}\end{array}$ \\
\hline Perception of not being at risk of being infected & $284(80.5)$ \\
Fear of testing positive & $69(19.5)$ \\
Perception of being healthy without a need for VCT & $66(18.7)$ \\
Lack of time & $52(14.7)$ \\
Fear of stigmatization and discrimination & $34(9.6)$ \\
Lack of awareness of where the test is available & $29(8.2)$ \\
Inability to afford the test /Cost & $20(5.7)$ \\
Fear of breach of confidentiality & $20(5.7)$ \\
Lack of awareness of VCT & $20(5.7)$ \\
Fear of death & $14(4.0)$ \\
Fear of rejection by partner & $11(3.1)$ \\
Lack of partner's approval & $3(0.8)$ \\
\hline
\end{tabular}

*There were multiple responses

Table 3: Binary logistic regression analysis assessing association between selected variables and HCT uptake

\begin{tabular}{|c|c|c|c|c|c|c|c|c|}
\hline \multicolumn{7}{|l|}{ Explanatory } & \multicolumn{2}{|c|}{$95 \%$ CI for OR } \\
\hline Variables & $\mathbf{B}$ & S.E. & Wald & Df & $\mathbf{P}$ & OR & Lower & Upper \\
\hline Sexually experienced & 0.270 & 0.222 & 1.471 & 1 & 0.225 & 1.310 & 0.847 & 2.026 \\
\hline \multicolumn{2}{|l|}{ *Risk Perception } & & 12.366 & 4 & 0.015 & & & \\
\hline Great & -0.195 & 0.299 & 0.424 & 1 & 0.515 & 0.823 & 0.458 & 1.479 \\
\hline Moderate & 0.905 & 0.297 & 9.280 & 1 & 0.002 & 2.472 & 1.381 & 4.424 \\
\hline Unsure & 0.297 & 0.232 & 1.638 & 1 & 0.201 & 1.346 & 0.854 & 2.122 \\
\hline Small & 0.300 & 0.183 & 2.693 & 1 & 0.101 & 1.350 & 0.943 & 1.932 \\
\hline $\begin{array}{l}\text { *Partner } \\
\text { status }\end{array}$ & Screening & & 77.360 & 3 & 0.000 & & & \\
\hline No & -1.533 & 0.225 & 46.391 & 1 & 0.000 & 0.216 & 0.139 & 0.336 \\
\hline No partner & -1.562 & 0.257 & 36.879 & 1 & 0.000 & 0.210 & 0.127 & 0.347 \\
\hline Don't know & -1.408 & 0.196 & 51.625 & 1 & 0.000 & 0.245 & 0.167 & 0.359 \\
\hline \multicolumn{2}{|l|}{ HCT has advantages } & & 2.381 & 2 & 0.304 & & & \\
\hline Don't know & -0.701 & 0.477 & 2.164 & 1 & 0.141 & 0.496 & 0.195 & 1.263 \\
\hline No & -0.211 & 0.410 & 0.264 & 1 & 0.608 & 0.810 & 0.362 & 1.810 \\
\hline \multicolumn{2}{|l|}{ Religion } & & 2.601 & 2 & 0.272 & & & \\
\hline Others & -0.111 & 0.531 & 0.044 & 1 & 0.834 & 0.895 & 0.316 & 2.535 \\
\hline Muslim & -0.421 & 0.262 & 2.595 & 1 & 0.107 & 0.656 & 0.393 & 1.096 \\
\hline \multicolumn{2}{|l|}{ Ethnic group } & & 6.768 & 3 & 0.080 & & & \\
\hline Hausa & -0.208 & 0.330 & 0.395 & 1 & 0.530 & 0.813 & 0.425 & 1.552 \\
\hline Yoruba & -0.435 & 0.223 & 3.815 & 1 & 0.051 & 0.647 & 0.418 & 1.002 \\
\hline Ibo & 0.183 & 0.176 & 1.083 & 1 & 0.298 & 1.201 & 0.851 & 1.696 \\
\hline Constant & 0.976 & 0.185 & 27.904 & 1 & 0.000 & 2.654 & & \\
\hline
\end{tabular}

\section{Model Summary}

Cox and Snell $\mathrm{R}^{2}$ 


\begin{tabular}{|c|c|c|c|c|c|c|c|c|}
\hline \multirow{2}{*}{$\begin{array}{l}\text { Explanatory } \\
\text { Variables }\end{array}$} & \multirow[b]{2}{*}{ B } & \multirow[b]{2}{*}{ S.E. } & \multirow[b]{2}{*}{ Wald } & \multirow[b]{2}{*}{ Df } & \multirow[b]{2}{*}{$\mathbf{P}$} & \multirow[b]{2}{*}{ OR } & \multicolumn{2}{|c|}{$95 \% \mathrm{CI}$ for OR } \\
\hline & & & & & & & Lower & Upper \\
\hline Sexually experienced & 0.270 & 0.222 & 1.471 & 1 & 0.225 & 1.310 & 0.847 & 2.026 \\
\hline \multicolumn{2}{|l|}{ *Risk Perception } & & 12.366 & 4 & 0.015 & & & \\
\hline Great & -0.195 & 0.299 & 0.424 & 1 & 0.515 & 0.823 & 0.458 & 1.479 \\
\hline Moderate & 0.905 & 0.297 & 9.280 & 1 & 0.002 & 2.472 & 1.381 & 4.424 \\
\hline Unsure & 0.297 & 0.232 & 1.638 & 1 & 0.201 & 1.346 & 0.854 & 2.122 \\
\hline Small & 0.300 & 0.183 & 2.693 & 1 & 0.101 & 1.350 & 0.943 & 1.932 \\
\hline $\begin{array}{l}\text { *Partner } \\
\text { status }\end{array}$ & Screening & & 77.360 & 3 & 0.000 & & & \\
\hline No & -1.533 & 0.225 & 46.391 & 1 & 0.000 & 0.216 & 0.139 & 0.336 \\
\hline No partner & -1.562 & 0.257 & 36.879 & 1 & 0.000 & 0.210 & 0.127 & 0.347 \\
\hline Don't know & -1.408 & 0.196 & 51.625 & 1 & 0.000 & 0.245 & 0.167 & 0.359 \\
\hline \multicolumn{2}{|l|}{ HCT has advantages } & & 2.381 & 2 & 0.304 & & & \\
\hline Don't know & -0.701 & 0.477 & 2.164 & 1 & 0.141 & 0.496 & 0.195 & 1.263 \\
\hline No & -0.211 & 0.410 & 0.264 & 1 & 0.608 & 0.810 & 0.362 & 1.810 \\
\hline \multicolumn{2}{|l|}{ Religion } & & 2.601 & 2 & 0.272 & & & \\
\hline Others & -0.111 & 0.531 & 0.044 & 1 & 0.834 & 0.895 & 0.316 & 2.535 \\
\hline Muslim & -0.421 & 0.262 & 2.595 & 1 & 0.107 & 0.656 & 0.393 & 1.096 \\
\hline \multicolumn{2}{|l|}{ Ethnic group } & & 6.768 & 3 & 0.080 & & & \\
\hline Hausa & -0.208 & 0.330 & 0.395 & 1 & 0.530 & 0.813 & 0.425 & 1.552 \\
\hline Yoruba & -0.435 & 0.223 & 3.815 & 1 & 0.051 & 0.647 & 0.418 & 1.002 \\
\hline Ibo & 0.183 & 0.176 & 1.083 & 1 & 0.298 & 1.201 & 0.851 & 1.696 \\
\hline Nagelkerke $\mathrm{R}^{2}$ & 0.189 & & & & & & & \\
\hline
\end{tabular}

\section{Discussion}

The study revealed that well over half of the respondents had been counselled and tested for HIV. This is higher than the uptake reported by most Nigerian studies. For example, some studies conducted among students in tertiary institutions in South Eastern and South Western Nigeria reported 26.4 and 5.0\% HCT uptakes respectively ${ }^{[11,13]}$ A study conducted among university students in Uganda reported that only $28 \%$ of them had ever taken the HIV test. ${ }^{[14]}$ In addition, a multi-center study conducted among university students in South Africa, India and USA reported 20.0, 20.0 and 10.0\% HCT uptakes among the South African, American and Indian students respectively. ${ }^{[15]}$

The higher level of uptake obtained in the study might suggest increased awareness and acceptance of HCT among students of tertiary institutions. This can also be attributed to increased media publicity that is being given to HCT in recent times. The establishment of Youth Friendly HCT centres in some of our high institutions of learning, coupled with the availability of rapid kits test which makes it possible for HCT to be made available at conferences, seminars, religious and other public gatherings, can further explain the increased uptake.

The major reasons for accessing HCT were respondents' desire to know their HIV status (59.8\%), to reduce fear and anxiety $(18.7 \%)$ and concern about risk of infection (18.5\%). Different studies elicited information on various reasons for accessing HCT, some of which differed from the questions asked in this study. However, among those whose questions were similar to those in this study, the most important reason for accessing HCT was equally people's desire to know their HIV status ${ }^{[10,13,14]}$ Other reasons given for accessing HCT included fear and anxiety over HIV status; as marriage requirements, for employment purposes, concern about risk of infection and desire to travel overseas ${ }^{[10,13,14,16]}$

Differences in the reasons given for accessing HCT services can be due to the different populations studied, their perception of the risk of acquiring HIV and about who really requires HCT services. Among pregnant women, ante-natal care requirements may rank higher while issues about employment, marriage, and desire to travel overseas may rank higher among youths. Despite being at risk, people with poor risk perception may rank concern about risk of infection very low on their list while those who think that HCT is only for the sick might access it only if, and when they are sick.

In this study, the most important reason for not accessing HCT among respondents who had not been tested for the virus was perception of not being at risk of being infected. This is similar to the findings of studies conducted among youths in Uganda and Nigeria which showed that the commonest reason for not accessing HCT was because they were certain that they were not infected ${ }^{[13,14]}$ Poor risk perception for HIV/AIDS has 
been noted to be common among young people and underscores the need for interventions that can enable youths to correctly perceive their HIV/AIDS risk and also effect behavioural changes that will make them less predisposed to the disease.

The second most important reason for not accessing HCT services was fear of testing positive. The fear of knowing one's test result was the most frequent reason given for not testing for HIV. This was consistent with findings from other studies ${ }^{[14,15,17,18]}$

The third most important reason for not accessing HCT services was perception of being healthy without a need for HCT services. This is corroborated by the reports of studies conducted in Nigeria, South Africa and Zambia which equally reported that those who felt they were healthy did not access HCT. The mindset that HCT is only for the sick has grave implications for the control of HIV/AIDS, a disease with a long incubation period ${ }^{[19]}$ Most infected people look healthy for a long time and might not realize their need for HCT services until they become symptomatic. Learning about one's HIV status on time allows people to access care, support and treatment early if positive; and to make some important life decisions. It encourages those who are negative to continue their HIV preventive behaviours. The policy implication is that HIV/AIDS education should be intensified via the media, especially the fact that people can be infected and yet look healthy. The benefits of accessing HCT services early should also be emphasized.

One of the factors which significantly predicted HCT uptake in this study was self perceived risk of HIV. Compared with respondents who felt they had no risk of HIV, those that felt they had moderate risk were significantly more likely to access HCT. Surprisingly enough, those who perceived themselves to be at great risk for HIV were less likely to access HCT (though this was not significant). The result of this study is similar in part to some studies while it contrasts with some others. A study conducted in Tanzania showed that poor risk perception is negatively correlated with HCT uptake while high risk perception is positively correlated with HCT uptake. ${ }^{[20]}$ Similarly, another study conducted in Uganda reported that those who perceived themselves to be at high risk of HIV infection were about five times more likely to be willing to be tested than those who perceived themselves as low risk. ${ }^{[21]}$ The fact that those who perceived themselves to be at great risk of HIV infection were less likely to test, contrast with these studies.

Some studies conducted in Zambia however reported that even though self-perceived risk of HIV was positively associated with initial willingness to test, it was not associated with actually accepting the test ${ }^{[19,22]}$ It is possible that fear of a positive result, of breach of confidentiality or of stigmatization could have prevented those who perceived themselves at high risk from accessing HCT services.

Sexual partner's HIV screening status also significantly influenced HCT uptake by respondents in this study. Respondents whose sexual partners had been screened for HIV were more likely to access HCT compared with those whose partners had not been screened, those who were not sure whether their partners had been screened and those who had no partners. This finding is corroborated by the report of a study conducted in South Western Nigeria in which those whose partners had been screened for HIV were more likely to access HCT services. ${ }^{[23]}$ Another study conducted among Ethiopian youth equally reported that those whose friends had tested for HIV were more likely to access HCT. ${ }^{[24]}$ This finding is in keeping with one of the constructs of the Health Belief Model (cues to action). Cues to action are internal and external stimuli perceived by the individual that further makes him/her to take a health action. ${ }^{[25]}$ In addition, it corroborates the result of a study which showed that people tend to take up those behaviours that their friends, spouses or relatives do, or approve of $^{[26]}$

\section{Conclusion}

The HCT uptake among corps members in this study was fair. The most important reasons for accessing HCT were desire to know their HIV status; in order to reduce fear and anxiety and concern about risk of infection. The most important reasons for not accessing HCT services among those who had not done so were poor perception of the risk of infection, fear of testing positive and perception of being healthy without a need for HCT. The predictors of HCT uptake were self perception of the risk of HIV infection and partner's screening status. Health education to make people appreciate their risk of HIV better and recognize the benefits of HCT should be intensified.

\section{Acknowledgement}

The authors would like to acknowledge the corps members who were interviewed.

\section{References}

[1] Joint United Nations Programme on HIV/AIDS (UNAIDS), Fact sheets: United Nations special session on HIV/AIDS: global crisis-global action, (New York: United Nations Department of Public Information and UNAIDS, 2001) 41

[2] A.O. Lucas, H.M. Gilles, Infections transmitted through human contacts, in A.O. Lucas, H.M. Giles (Eds.), Short textbook of public health for the tropics, 4 (Malta, Book Power, 2003) 108-113. 
[3] W.T. A. Todd, D.N. J. Lockwood, F.J. Nye, E.G. Wilkins, P.B. Carey, Infection and immune failure, human immunodeficiency virus infection and the human acquired immunodeficiency syndrome, in C. Haslets, E.R. Chilvers, J.A.A. Hunter, N.A. Boon (Eds.), Davidson's principles and practice of medicine. (Edinburgh, Churchill Living Stone, 2002) 108-133.

[4] M.O. Bachmann, F.L.R. Booysen, Health and economic impact of HIV/AIDS on South African households: a cohort study, BMC Public Health, 2003, 3:14 doi:10.1186/1471-2458-3-14

[5] Population Reference Bureau, Population, reproductive rights and reproductive health with special reference to HIV/AIDS: a concise report, (New York, United Nations Department of Economic and Social affairs, Population Division, 2004) Available from:http://www.amazon.com/Population-Reproductive-Rights-Special-Reference/dp/sitb-next/9211513731 . [Accessed on 24.01.2013].

[6] Federal Ministry of Health, National HIV/AIDS sero-prevalence sentinel survey among ante-natal clinic attendees, (Abuja, Nigeria, Federal Ministry of Health, 2008)

[7] World Health Organization, Young people's health: a challenge for society: report of a WHO study group on young people and "health for all by the year 2000", (Geneva, WHO, 1986).

[8] Joint United Nations Programme on HIV/AIDS (UNAIDS), Listen, learn, live: world AIDS campaign with children and young people, facts and figures. (Geneva: UNAIDS, 1999) 4. Available from: URL: http://www.unaids.org/wac/1999/eng/facts-e.pdf,

[9] D. Boswell, R. Baggaley, Voluntary counselling and testing and young people: a summary overview, VCT Toolkit, (Family Health International, 2002).

[10] Federal Ministry of Health, 2005 National HIV/AIDS and reproductive health survey, (Abuja: Federal Ministry of Health, 2006)

[11] K.T. Ijadunola, T.C. Abiona, O.O. Odu, M.Y. Ijadunola, College students in Nigeria underestimate their risk of contracting HIV/AIDS infection, European Journal of Contraception and Reproductive Health Care, 12(2), 2007, 131-137.

[12] S.O. Bamiwuye, Obstacles to HIV/AIDS risk-reduction behaviour among students in south-western Nigerian universities, doctoral diss. Obafemi Awolowo University, Ile-Ife, Nigeria, 2006.

[13] I.J. Ikechebelu, C.O. Udigwe, N. Ikechebelu, L.C. Imoh, The knowledge, attitude and practice of voluntary counselling and testing (VCT) for HIV/AIDS among undergraduates in a polytechnic in South East Nigeria, Nigerian Journal of Medicine, 15(3), 2006, 245-249.

[14] A.M. Muganga, M.E. Bahemuka, C.O. Ariono, R.B. Denis, Knowledge and acceptability of HIV voluntary counselling and testing among Ugandan urban youth. Proc. Conf. on AIDS, 2002, 14

[15] K. Peltzer, E. Nzewi M. Krishna, Attitudes towards HIV-antibody testing and people with AIDS among university students in India, South Africa and United States, Indian Journal of Medical Sciences, 58, 2004, 95-108.

[16] A.E. Meibergl, A.E.R. Bos, H.E. Onya, H.P. Schaalmal, Fear of stigmatization as barrier to voluntary HIV counselling and testing in South Africa, East African Journal of Public Health, 5(2), 2008, 49.

[17] M. Hamill, A. Copas, S.M. Murphy, Incentives for voluntary HIV testing in NHS staff, Occupational Medicine, 56, 2004, 26-429.

[18] S.D. Weiser, M. Heisler, K. Leiter, F.P. Korte, S. Tlou, S. DeMonner, et al, Routine HIV testing in Botswana: a population-based study on attitudes, practices, and human rights concerns, Plos Medicine, 3, 2006, e261

[19] K. Fylkesnes, S. Siziya, Factors influencing readiness for and acceptability of voluntary HIV counselling and testing, Tropical Medicine and International Health, 9(5),2009, 556-572.

[20] M.M. De Paoli, K.I. Klepp, Factors influencing acceptability of voluntary counseling and HIV-testing among pregnant women in Northern Tanzania, AIDS Care, 16(4), 2004, 411-25

[21] J. Degu, E. Aschalew, L. Bernt, Acceptability of HIV counselling and testing among tuberculosis patients in South Ethiopia, BMC International Health and Human Rights, 2007, 7:4doi:10.1186/1472-698X-7- Retrieved from http://www.biomedcentral.com/1472$698 X / 7 / 4$ accessed 11 th May 2009.

[22] K. Fylkesnes, A. Haworth, C. Rosensvärd, P.M. Kwapa, HIV counselling and testing: overemphasizing high acceptance rates, a threat to confidentiality and the right not to know, AIDS, 13(17), 2469-2474.

[23] E.O. Amu, K.T. Ijadunola, J.O. Bamidele, O.O. Odu, Barriers to and determinants of HIV counselling and testing among adults in Ayedaade Local Government Area, Osun State, Nigeria, Journal of Medical Sciences, 2013 doi:10.3923/jms.2013

[24] A. Dirar, B. Mengiste, H. Kedir, W. Godana, Factors contributing to voluntary counselling and testing uptake among youth in colleges of Harar, Ethiopia, Science Journal of Public Health, 1(2), 2013, 91-96. doi: 10.11648/j.sjph.20130102.17

[25] M.H. Becker, The health belief model and personal health behavior, Health Education Monographs, 2, 1974, $324-508$

[26] A.S. Jegede, Culture bound terminology in the interpretation of illness in the Yoruba community of Nigeria, Journal of Contemporary Health, 4, 1996, 74-75.

\section{CONFLICT OF INTEREST}

We, the authors declare that there is no conflicts of interest that might bias our work or inappropriately influence our judgment. 